\title{
AS CONTRIBUIÇÕES DA TECNOLOGIA ASSISTIVA DOSVOX PARA PROFESSORES EM FORMAÇÃO INICIAL: INTERMEDIANDO PRÁTICAS TECNOLÓGICAS INCLUSIVAS
}

\author{
LAS CONTRIBUICIONES DE LA TECNOLOGÍA DE ASISTENCIA DOSVOX PARA \\ MAESTROS EN FORMACIÓN INICIALES: PRÁCTICAS INCLUSIVAS \\ INTERMEDIAS
}

\begin{abstract}
THE CONTRIBUTIONS OF DOSVOX ASSISTIVE TECHNOLOGY FOR INITIAL TRAINING TEACHERS: INTERMEDIATING INCLUSIVE TECHNOLOGICAL PRACTICES
\end{abstract}

\author{
Eliziane de Fátima ALVARISTO ${ }^{1}$ \\ Jamile SANTINELLO ${ }^{2}$
}

RESUMO: O estudo tem como objetivo contribuir com a formação inicial de professores de um curso de Pedagogia por meio da Tecnologia Assistiva - Dosvox, tendo em vista a concepção de ensino e aprendizagem inclusiva para estudantes com deficiência visual. Utilizou-se da abordagem qualitativa de natureza aplicada, tendo como estratégia de pesquisa o estudo de caso. O estudo foi realizado em uma instituição pública de ensino superior, localizada no interior do estado do Paraná, e traz como participantes vinte e cinco professores em formação inicial de um curso de Pedagogia e um professor cego. Os instrumentos utilizados para a análise dos dados foram: gravações em áudio e vídeo, fotos e intervenção prática sobre o uso da Tecnologia Assistiva - Dosvox. Os dados foram analisados a partir da teoria Histórico-Cultural. Os resultados revelam que as intervenções realizadas pelo professor cego aos professores em formação inicial de um curso de Pedagogia contribuíram com a aquisição de novas concepções sobre o processo de ensino e aprendizagem inclusivo da Tecnologia Assistiva - Dosvox, possibilitando aos professores reconhecerem-se e autoavaliarem-se pedagogicamente no processo de ensino inclusivo às pessoas com deficiência visual, dentre eles, no modo de ensinar e aprender com um professor cego.

PALAVRAS-CHAVE: Formação inicial de professores. Tecnologia Assistiva Dosvox. Deficiência visual. Inclusão. Ensino superior.

RESUMEN: El estudio tiene como objetivo contribuir a la formación inicial de los docentes em un curso de pedagogía a través de la tecnología de asistencia - Dosvox, em vista del concepto de enseñanza y aprendizaje inclusivo para estudiantes con discapacidad visual. Se utilizó un enfoque cualitativo de carácter aplicado, con el estudio de caso como estrategia de

1 Universidade Estadual do Centro-Oeste (UNICENTRO), Guarapuava - PR - Brasil. Professora do Departamento de Pedagogia, Professora no Centro de Atendimento Especializado na área de deficiência visual (CAEE) e Professora de Sala de Recursos Multifuncionais - SEMEC. Doutoranda no Programa de PósGraduação em Educação (UNICENTRO). ORCID: https://orcid.org/0000-0002-1549-4176. E-mail: elizianealvaristo@unicentro.br

${ }^{2}$ Universidade Estadual do Centro-Oeste (UNICENTRO), Guarapuava - PR - Brasil. Professora no Programa de Pós-Graduação em Educação e no Departamento de Pedagogia. Doutorado em Comunicação (UFRJ). ORCID: https://orcid.org/0000-0003-1136-2421. E-mail: jamile@unicentro.br

RIAEE - Revista Ibero-Americana de Estudos em Educação, Araraquara, v. 16, n. esp. 4, p. 3086-3105, dez. 2021. e-ISSN: 1982-5587 
investigación. Se llevó a cabo en una Institución Pública de Educación Superior, ubicada en interior del estado de Paraná, y reúne como participantes a veinticinco maestros en capacitación inicial en un curso de pedagogía y uno maestro ciego. Los instrumentos utilizados para el análisis de datos fueron: grabaciones de audio y video, fotos e intervención práctica sobre el uso de la tecnología de asistencia - Dosvox. Los datos fueron analizados a partir de la teoría Histórico-Cultural. Los resultados revelan que las intervenciones realizadas por el maestro ciego a los maestros em la capacitación inicial de un curso de pedagogía contribuyeron a la adquisición de nuevos conceptos sobre el proceso inclusivo de enseñanza y aprendizaje de la tecnología de asistencia - Dosvox, permitiendo a los maestros reconocerse y autoevaluarse pedagógicamente en el proceso de educación inclusiva para personas con discapacidad visual, entre ellos, en la forma de enseñar y aprender con un maestro ciego.

PALABRAS CLAVE: Formación inicial del maestro. Tecnología de Asistencia Dosvox. Discapacidad visual. Inclusión. Enseñanza superior.

ABSTRACT: The study aims to contibute to the initial training of teachers in a Pedagogy course through Assistive Technology - Dosvox, in view of the concepto of inclusive teaching and learning for students with visual impairments. For this study, a qualitative approach of an applied nature was used, having as a research strategy the case study. It was carried out in a public institution of higher education, located in the interior of the Paraná, and brings as participants twenty-five teachers in initial formation of a course of pedagogy and a blind teacher. The instruments used for data analysis were: audio and video recordings, photos and practical intervention on the use of Assistive Technology - Dosvox. The data were analyzed from the historical-cultural. The results reveal that the interventions carried out by the blind teacher to the teachers in the initial formation of a pedagogy course contributed to the acquisition of new conceptions about the inclusive teaching and learning processo of Assistive Technology - Dosvox, allowing teachers to recognize and self-assess themselves pedagogically in the process of inclusive education for people with visual impairments, among, them, in the way of teaching and learning with a blind teacher.

KEYWORDS: Initial teacher training. Dosvox Assistive Technology. Visual impairment. Inclusion. Higher education.

\section{Introdução}

As propostas sobre o uso da Tecnologia Assistiva - TA em salas de aula têm sido muito discutidas por profissionais da área da educação, haja vista que ela tange perspectivas por melhorias no processo de aprendizagem inclusiva de estudantes com deficiência, transtornos globais do desenvolvimento e altas habilidades/superdotação, incluídos na Política Nacional de Educação Especial na Perspectiva da Educação Inclusiva (BRASIL, 2008).

Nesse sentido, considera-se a acessibilidade como um direito de todo e qualquer cidadão com quaisquer tipos de deficiência, previstos na lei federal $\mathrm{n}^{0} 10.098$, de 19 de dezembro do ano 2000, assim como em (BRASIL, 1988; DECLARAÇÃO DE 
SALAMANCA, 1994; BRASIL, 1996; 2008; 2015). Portanto, é fundamental que novas reflexões e novas propostas sobre o uso da TA em salas de aula sejam revistas como um meio de acesso para comunicação e interação à cultura digital nos ambientes educacionais de ensino de modo mais inclusivo.

Tendo em vista a importância da TA, Alves et al. (2009) conceituam a TA como recursos, metodologias, estratégias e práticas que possibilitam aos estudantes com deficiência maior autonomia, qualidade de vida e inclusão social.

Nesta direção, este estudo buscou enfatizar a TA - Dosvox. Considerada um sistema de programação que se comunica com os usuários através da síntese de voz, ou seja, o computador por meio de um sintetizador de voz realiza a leitura da tela ao usuário. A TA Dosvox é totalmente nacional, considerada o primeiro sistema comercial a sintetizar vocalmente textos genéricos para a língua portuguesa, viabilizando o uso de computadores por pessoas com deficiência visual, e possibilitando maior acessibilidade tecnológica, comunicação e interação (SOUZA; SANTAROSA, 2003).

A TA - Dosvox vem sendo desenvolvida desde o ano de 1993, pela Universidade Federal do Rio de Janeiro - UFRJ. Assim, alguns estudos (DIAS; FRANÇA; BORGES, 2014; MAZZILLO, 2010; BORGES, 2009) ressaltam sobre a importância de fazer uso dessa tecnologia em sala de aula com alunos com deficiência visual, pois os possibilita melhor aprendizado e maiores perspectivas inclusivas.

Conforme Galvão Filho (2009), apesar da TA - Dosvox possibilitar a acessibilidade às pessoas com deficiência visual, há necessidade de os professores buscarem maior formação sobre a funcionalidade e uso do sistema de programação da tecnologia, pois a qualidade de ensino é essencial em sala de aula, principalmente no processo inicial de estudantes com deficiência visual, nos anos iniciais do ensino fundamental.

De acordo com Prais e Rosa (2017), a temática sobre a formação dos professores tem gerado muitas discussões frente à necessidade emergente para se efetivar a educação inclusiva de pessoas com alguma deficiência em sala de aula. Os autores retratam carência na formação pedagógica dos professores. Para prestar atendimento pedagógico às pessoas com deficiência com qualidade no processo de ensino e aprendizagem, as escolas de ensino regular precisam realizar flexibilizações/adaptações curriculares e estratégias pedagógicas que consistem basicamente na tomada de decisão dos professores juntamente com a equipe pedagógica, buscando proporcionar uma ação educativa escolar que atenda as peculiaridades dos estudantes com deficiência, possibilitando assim um currículo mais dinâmico, alterável e 
passível de ampliação que atenda a todos os estudantes, sem perda de conteúdo (BRASIL, 2003).

Nesse sentido, esse estudo objetiva contribuir com a formação inicial de professores de um curso de Pedagogia por meio da TA - Dosvox, tendo em vista a concepção do processo de ensino e aprendizagem inclusivo a estudantes com deficiência visual, pensando no processo de ensino de forma mais inclusiva.

\section{A contribuição da Tecnologia Assistiva Dosvox para pessoas com deficiência visual}

A TA - Dosvox é considerada como um dos recursos didáticos tecnológicos utilizados para o processo de ensino e aprendizagem de estudantes com deficiência visual em salas de aula. Esta tecnologia disponibiliza a possibilidade de acessibilidade digital e inclusiva para estes estudantes. Nesta direção, Sonza e Santarosa (2003) evidenciam em seus estudos a acessibilidade que a TA - Dosvox pode promover, e destacam que tanto o Software quanto o Hardware são projetos originais e de baixa complexidade, adequados à realidade dos estudantes com deficiência visual, bem como detalha as modificações que o sistema vem sofrendo em suas versões, sendo a última a versão 5.0c (BORGES, 2009).

O sistema de programação da TA - Dosvox se constitui como um leitor de tela que utiliza de sintetizadores de voz, permitindo a leitura e as informações na tela do computador pelo usuário. Está disponível para pessoas com deficiência visual e as demais que tiverem interesse em utilizá-lo. O programa é distribuído nas versões para Windows.

A Figura 1 apresenta alguns dos programas contidos na versão 5.0c da TA - Dosvox.

Figura 1 - Tela do Sistema Dosvox versão 5.0c

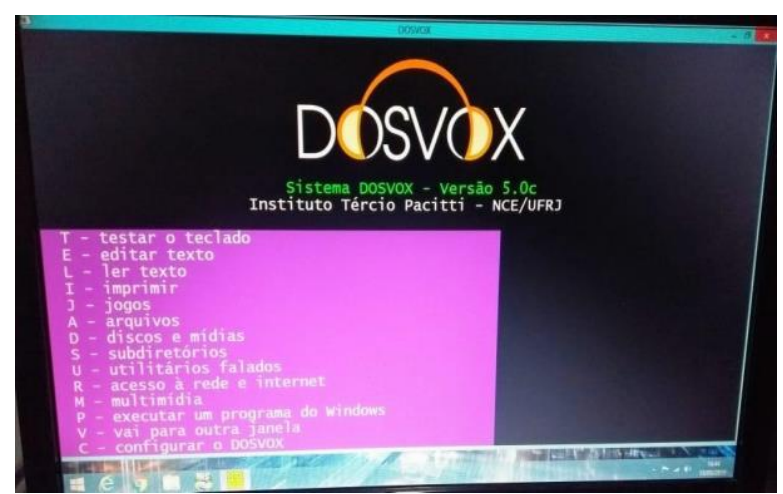

Fonte: Acervo das pesquisadoras (2019)

Borges (2002), juntamente com o Núcleo de Computação Eletrônica - NCE, salientam que o desenvolvimento da TA - Dosvox possibilita maior tecnologia da computação, 
rompendo com barreiras e possibilitando às pessoas com deficiência visual escrever e ler o que os outros escrevem, pois até então o sistema Braille era utilizado apenas por pessoas que dele tinham conhecimento, ou seja, uma minoria.

Conforme Sá, Campos e Silva, (2007, p. 23), o sistema Braille “[...] é composto por seis (6) pontos combinados entre si, com um total de 63 possibilidades. Criado por Louis Braille como forma de linguagem escrita para pessoas com deficiência visual". Antes do desenvolvimento da TA - Dosvox, Borges (2009, p. 99) salienta que "[...] as pessoas cegas viviam num gueto cultural, onde um cego só escrevia para outro cego ler", porém, nesse contexto atual tudo está diferente, os cegos podem se comunicar e usufruir da tecnologia como qualquer outra pessoa vidente, eles têm acesso a várias informações e conhecimentos. Considera-se que o advento do computador é uma fonte para a inclusão digital das pessoas com deficiência visual.

Neste viés, Moran (2013) evidencia que as TA são consideradas uma inovação para o âmbito educacional de ensino e são essenciais para o desenvolvimento dos estudantes, pois possibilitam a comunicação e a interação, sendo fundamentais para o processo de ensino, visto que se integram, se completam e se combinam. Sendo assim, é importante ressaltar que a TA - Dosvox é um recurso importante para a acessibilidade de estudantes com deficiência visual.

É importante destacar que há outras TA que podem ser utilizadas como recursos didáticos em salas de aula por estudantes com deficiência visual, as quais também possibilitam a inclusão digital e a comunicação, dentre elas, Virtual Vision, Jaws e o NVDA. Porém, esse estudo buscou abordar a TA - Dosvox devido à gratuidade e à facilidade de acesso para qualquer usuário com deficiência visual. Para Borges (2002), a maior diferença entre o Dosvox e os demais programas computacionais que estão disponíveis para auxiliar os estudantes com deficiência visual reside no fato de que o Dosvox não é apenas "[...] uma casca de interface colocada sobre os programas convencionais, mas um ambiente operacional totalmente projetado com características de comunicação coerentes com as do cego" (BORGES, 2002, p. 23). Essas características de comunicação visam a considerar as particularidades das pessoas com deficiência visual, a possibilitar maior interação social, cultural e de acessibilidade digital.

Conforme Borges (2002), a TA - Dosvox amplia o processo de comunicação e a relação social. Isso remete à luz da teoria de Vygotsky (1997), médico, professor e psicólogo, considerado como um dos pioneiros em estudos sobre o desenvolvimento de pessoas com deficiência. $\mathrm{O}$ autor desenvolveu a teoria Histórico-Cultural, a qual discute a relação entre a 
aprendizagem e o desenvolvimento da criança a partir de mediações e relações sociais e culturais. Segundo Vygotsky (1997), os meios aplicados no processo de aprendizagem de pessoas cegas iniciam-se, frequentemente, com sua cultura, propondo:

[...] formas culturais peculiares, especialmente criadas para o desenvolvimento cultural da criança com deficiência. A ciência conhece uma série de sistemas culturais artificiais que oferecem interesse teórico. Junto com o alfabeto visual, que é usado por toda a humanidade, um alfabeto tátil especial de caracteres pontilhados foi criado para cegos [...] os processos de domínio e uso desses sistemas culturais auxiliares são distinguidos por sua profunda peculiaridade em comparação com o uso dos meios usuais de cultura (VYGOTSKY, 1997, p. 27, tradução nossa) ${ }^{3}$.

Diante dos avanços tecnológicos e das novas leis que regem o direito à educação das pessoas com deficiência visual, a TA - Dosvox possibilita para além de ler com as mãos, e indica novos caminhos voltados para a inclusão digital transformadora e com equidade de direitos sociais, culturais e tecnológicos. Para Vygotsky (1997), o termo cultural e social deve estar contextualizado com a realidade das pessoas com deficiência visual para que o efeito da inter-relação se torne constitutivo.

\section{Metodologia}

Este estudo é de natureza aplicada, tem por objetivo "[...] gerar conhecimentos para aplicação prática, dirigidos à solução de problemas específicos” (GERHARDT; SILVEIRA, 2009, p. 35).

Apresenta uma abordagem qualitativa. A estratégia que atende aos objetivos propostos é o estudo de caso, por se tratar das contribuições e desafios que serão enfrentados por professores em formação inicial de um curso de Pedagogia em sala de aula. Para Lüdke e André (1996), o ponto central do estudo de caso incide sobre suas particularidades, mesmo que, posteriormente, evidenciem-se semelhanças com outros casos ou situações. O estudo de caso visa à descoberta, acontece de forma contextualizada, retratando a realidade de forma complexa e profunda.

Este estudo foi desenvolvido em uma instituição pública de Ensino Superior, localizada no interior do estado do Paraná, contando com a participação de vinte e cinco professores em formação inicial de um curso de Pedagogia e um professor cego, o qual se

${ }^{3}$ [...] formas culturales peculiares, creadas especialmente para que se realice el desarrollo cultural del nino deficiente. La ciencia conoce una cantidad de sistemas culturales artificiales que ofrecen interés teórico. A la par con el alfabeto visual, que es utilizado por toda la humanidad, se ha creado para los ciegos un alfabeto especial táctil, de caracteres punteados [...] los procesos de dominio y utilización de estos sistemas culturales auxiliares se distinguen por su profunda peculiaridad en comparación con el uso de los medios habituales de la cultura (VYGOTSKY, 1997, p. 27). 
nominou como Joaquim, nome fictício a fim de manter sua identidade e integridade. $\mathrm{O}$ professor Joaquim atua como professor de informática e TA em uma escola de ensino fundamental na modalidade de educação especial. Os participantes aceitaram participar do estudo, assinaram o Termo de Consentimento Livre e Esclarecido (TCLE).

Os instrumentos utilizados para a coleta dos dados foram: gravações em áudio e vídeo, as quais foram transcritas na íntegra; fotos; intervenção prática para formação inicial dos professores. A intervenção teve duração de oito (8) aulas. O espaço e o tempo para a realização da intervenção foram disponibilizados por uma professora responsável pela disciplina de Novas Tecnologias Aplicadas à Educação na Instituição. Essa disciplina consta na grade do segundo ano $\left(2^{\circ}\right)$ do curso de Pedagogia. Segundo o Projeto Político Pedagógico (PPP) da Instituição, a disciplina tem por objetivo orientar sobre os Ambientes informatizados de aprendizagem; o papel da escola e do professor no processo ensino e aprendizagem, e na organização de atividades para a prática pedagógica utilizando o computador.

Dessa forma, a intervenção que foi conduzida pelo Professor Joaquim foi estruturada em três momentos: no primeiro momento os professores em formação inicial foram vendados durante a apresentação inicial da TA - Dosvox. No segundo momento, os professores não fizeram uso das vendas durante o processo da intervenção sobre a TA - Dosvox. Joaquim ensinou passo a passo aos professores sobre o sistema de programação Dosvox. No terceiro momento, os professores foram convidados a formar duplas, um deles foi vendado. Um professor representou o estudante cego e o outro fez o papel de professor mediador. Essa ação teve como finalidade mostrar aos professores por meio da prática como é ensinar estudantes com deficiência visual no uso da TA - Dosvox. Em todos os momentos da intervenção os participantes fizeram uso do computador/notebook.

As atividades desenvolvidas com os professores durante a intervenção foram realizadas a partir do seguinte questionamento: como o professor pode iniciar o ensino sobre a TA - Dosvox de forma inclusiva para estudantes com deficiência visual?

O Quadro 1 apresenta as atividades desenvolvidas para a intervenção realizada com os professores em formação inicial de um curso de Pedagogia.

Quadro 1 - Atividades desenvolvidas na intervenção pedagógica

\begin{tabular}{|c|c|c|c|}
\hline $\begin{array}{c}\text { CONTEÚDO TA - } \\
\text { DOSVOX }\end{array}$ & $\begin{array}{c}\text { MATERIAL } \\
\text { UTILIZADO }\end{array}$ & PROGRAMAS & OBJETIVOS \\
\hline $\begin{array}{c}\text { Contextualização } \\
\text { Histórica }\end{array}$ & $\begin{array}{c}\text { Notebook } \\
\text { Projetor multimídia }\end{array}$ & - & Apresentar a TA - Dosvox \\
\hline $\begin{array}{c}\text { Instalação do } \\
\text { Programa }\end{array}$ & Pendrive & TA - Dosvox & $\begin{array}{c}\text { Ensinar a facilidade para a } \\
\text { Instalação do programa }\end{array}$ \\
\hline
\end{tabular}

RIAEE - Revista Ibero-Americana de Estudos em Educação, Araraquara, v. 16, n. esp. 4, p. 3086-3105, dez. 2021. e-ISSN: 1982-5587 


\begin{tabular}{|c|c|c|c|}
\hline $\begin{array}{c}\text { Reconhecimento do } \\
\text { teclado por meio do } \\
\text { sintetizador de voz }\end{array}$ & $\begin{array}{c}\text { Notebook e Vendas para } \\
\text { olhos }\end{array}$ & Testando o teclado & $\begin{array}{c}\text { Identificar as teclas para } \\
\text { analisar o uso no sistema }\end{array}$ \\
\hline $\begin{array}{c}\text { Programas da TA - } \\
\text { Dosvox }\end{array}$ & $\begin{array}{c}\text { Notebook } \\
\text { Vendas para olhos } \\
\text { Projetor multimídia }\end{array}$ & $\begin{array}{c}\text { Edivox } \\
\text { Jogavox } \\
\text { Acesso à internet }\end{array}$ & $\begin{array}{c}\text { Apresentar e explorar cada } \\
\text { programa e seu uso }\end{array}$ \\
\hline $\begin{array}{c}\text { Programas da TA - } \\
\text { Dosvox }\end{array}$ & Notebook & TA - Dosvox & $\begin{array}{c}\text { Compreender o sistema da TA } \\
\text { Dosvox de modo geral }\end{array}$ \\
\hline $\begin{array}{c}\text { Programas da TA - } \\
\text { Dosvox }\end{array}$ & $\begin{array}{c}\text { Notebook } \\
\text { Vendas para olhos }\end{array}$ & TA - Dosvox & $\begin{array}{c}\text { Buscar enfatizar o processo } \\
\text { inicial de ensino aprendizagem } \\
\text { no uso TA inclusiva }\end{array}$ \\
\hline
\end{tabular}

Fonte: Acervo das pesquisadoras (2019)

A proposta para a intervenção do ensino sobre o uso inclusivo da TA - Dosvox foi elaborada a partir da concepção da teoria Histórico Cultural (VYGOTSKY, 1991; 1997).

\section{Resultados e Discussão}

A intervenção prática foi realizada pelo professor Joaquim para vinte e cinco professores em formação inicial de um curso de Pedagogia sobre a TA - Dosvox. Foi estruturada em três momentos, em todos os momentos fez-se uso do computador/notebook.

No primeiro momento foi proporcionado aos professores vivências de ensino sobre a TA - Dosvox com os olhos vendados, para que eles pudessem temporariamente perceber como as pessoas com deficiência visual aprendem e se relacionam. É relevante destacar que os professores participantes do estudo se sentiram pouco à vontade no primeiro contato com o professor Joaquim. A experiência mostrou duas circunstâncias: a primeira corresponde ao fato de o professor ser cego. A segunda leva-nos a refletir pelo fato de os professores em formação inicial não terem contado com nenhum professor cego nos espaços da universidade.

Frente a esse contexto, vale assinalar que independente da deficiência, todas as pessoas têm os mesmos direitos à educação sem qualquer discriminação (BRASIL 2015). Dessa forma, a intervenção prática teve como intuito impressionar os professores em formação inicial, para que eles pudessem compreender que é possível uma pessoa com deficiência visual ensinar e aprender nos mesmos ambientes educacionais de ensino que os demais estudantes. Nesta perspectiva, Kassar (2011) ressalta que, aos poucos, as políticas públicas são implementadas e conduzidas nas formações de professores, evitando-se assim situações que podem ser geradas por falta de informações sobre o processo inclusivo.

No entanto, após algumas interações e informações entre os professores em formação inicial e o professor Joaquim ocorreram as primeiras aproximações. Vários questionamentos 
foram levantados pelos professores. O que nos chamou a atenção foi quando uma professora perguntou ao professor Joaquim: “[...] se você nasceu cego como você fazia para estudar quando o professor passava algo no quadro para copiar? Alguém te auxiliava em sala de aula?" (PROFESSORA EM FORMAÇÃO INICIAL, 2019).

O professor Joaquim respondeu:

[...] antes do surgimento da TA - Dosvox eu utilizava o Braille, mas, após o desenvolvimento desta tecnologia o estado disponibilizava notebook, o que possibilitou muito meu desenvolvimento. O auxílio que eu tinha no processo de ensino-aprendizagem veio da escola de educação especial para pessoas com deficiência visual, em que os professores especializados na área davam apoio aos professores do ensino regular que eu estudava. Essa escola especializada que me auxiliou é a mesma que hoje eu atuo como professor (PROFESSOR JOAQUIM, 2019).

Constatou-se na resposta do professor Joaquim que é possível perceber a necessidade de maior formação dos professores que atuam na rede regular de ensino para o processo da inclusão. Segundo Dorziat (2014), este processo tem se agravado também pela superlotação de alunos em sala de aula, o que acaba sobrecarregando o trabalho dos professores. Nessa concepção, a autora esclarece que ainda nos tempos atuais não superamos o processo de discriminação nas salas de aula. Com isso, há muito trabalho pela frente para chegarmos ao processo inclusivo que possa impactar as práticas pedagógicas.

Diante de alguns questionamentos suscitados pelos professores no decorrer da intervenção prática, eles mostraram-se envolvidos com as propostas das atividades sobre a TA - Dosvox e, ao longo do processo, os professores foram percebendo que as pessoas com deficiência visual podem se destacar tanto quanto qualquer outra pessoa vidente (que enxerga) no processo de docência ao ensino. Após as mediações realizadas entre os participantes a intervenção prática iniciou-se, o professor Joaquim apresentou aos professores de modo geral algumas contextualizações históricas sobre o surgimento da TA - Dosvox (BORGES, 2009; 2002). Para maiores subsídios teóricos e práticos, o professor utilizou como recursos didáticos o notebook e um projetor multimídia, como mostra a Figura 2: 
Figura 2 - Professor Joaquim apresentando a TA - Dosvox aos professores em formação inicial

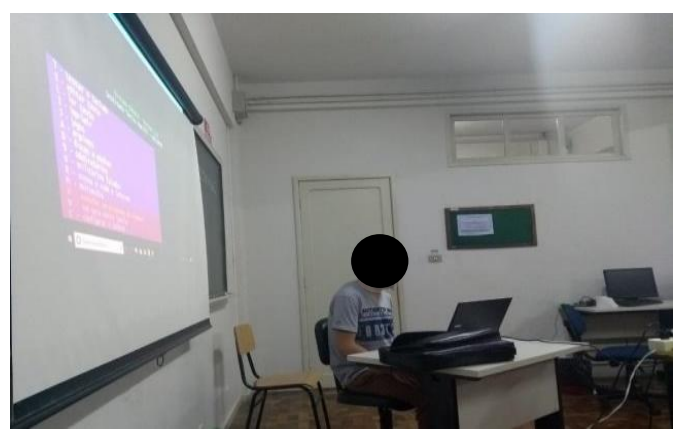

Fonte: Acervo das pesquisadoras (2019)

O professor Joaquim diante da sua intervenção esclarece aos professores que a tecnologia facilita a vida das pessoas com deficiência visual, pois ela permite novas fontes de comunicação, dentre elas, acessibilidade para maiores informações a outros meios culturais, conhecimentos científicos e entretenimento.

Após o professor finalizar sobre a contextualização histórica, iniciou-se o processo de ensino e acesso para a instalação do Programa Dosvox nos notebooks dos professores. Para a instalação, o professor Joaquim utilizou-se de um pendrive, como forma de aproveitamento do tempo. Porém, Borges (2009) destaca que o programa oficial disponibiliza o acesso da instalação direto à rede de internet. Durante a instalação, instruídos pelo professor Joaquim, os professores aprenderam como alterar os sintetizadores de voz no programa Dosvox.

Nesse ínterim do processo de instalação, foi possível observar que os professores demonstraram dificuldades para a instalação. Assim, necessitaram da intervenção individual do professor Joaquim para realização do processo. Esse momento foi essencial para os professores refletirem sobre o quanto é importante olhar para o outro sem preconceitos. Para Nunes e Lomônaco (2010, p. 59), as pessoas com deficiência visual são tidas como portadoras de características e estereótipos historicamente construídos pela sociedade, portanto, há necessidade de romper com essa concepção, pois “[...] esse preconceito impede que se perceba o cego como um ser humano".

Com a instalação do programa da TA - Dosvox concluída, os professores foram convidados a conhecer o programa de uma forma que intentava maiores aproximações com o colocar-se no lugar de uma pessoa com deficiência visual, "com os olhos vendados". Segundo o professor Joaquim, a didática utilizada teve como intuito possibilitar aos professores uma imersão do seu mundo, no sentido de como ele vê, sente e aprende, não utilizando a visão, mas outros sentidos. 
Nesta concepção de ensino e após todos os professores estarem vendados, o professor Joaquim iniciou a apresentação sobre TA - Dosvox a partir da atividade no Programa TESTAR O TECLADO. Este programa tem como intuito oportunizar aos estudantes cegos o reconhecimento do teclado. Assim, os professores vendados tiveram que identificar as teclas para analisar o que cada uma executa no sistema. Iniciou-se pelas letras do alfabeto contidas no teclado do computador/notebook a partir do tato e da audição.

A Figura 3 apresenta o momento da intervenção realizada com os professores com os olhos vendados.

Figura 3 - Intervenção prática: atividade testando o teclado

Fonte: Acervo das pesquisadoras (2019)

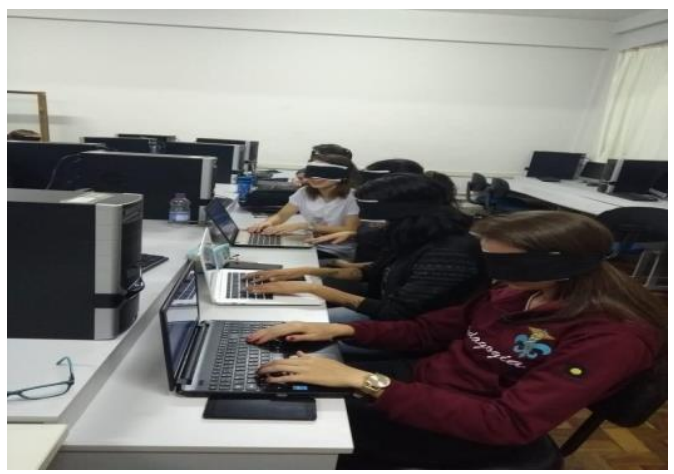

Frente à prática realizada, faz-se um paralelo ao que Vygotsky (1997) sinaliza sobre o que a falta de visão pode ocasionar. O teórico considera que a cegueira, ao criar uma nova e peculiar configuração de personalidade nas pessoas, origina "[...] novas forças, modifica as direções normais das funções, reestrutura e molda criativa e organicamente a psique do homem. Portanto, a cegueira não é apenas um defeito, uma deficiência, mas também, uma fonte de revelação de habilidades, uma vantagem, uma força" (VYGOTSKY, 1997, p. 99, tradução nossa) ${ }^{4}$.

Vale salientar que o professor Joaquim, por diversas vezes durante o processo da intervenção, evidencia que o momento proporcionado aos professores vendados faz com que eles se colocassem no seu mundo, compreendendo por meio prático como as coisas podem ser vistas. Nessa direção, Vygotsky (1997) enfatiza que a pessoa com deficiência visual utiliza outros sentidos para aprender e se envolver nos espaços sociais, portanto, é importante que os mediadores do conhecimento se envolvam com práticas necessárias para novas mudanças de ver, pensar e repensar suas ações.

${ }^{4}[\ldots]$ nuevas fuerzas, modifica las direcciones normales de las funciones, reestructura y forma creativa y organicamente la psique del hombre. Por consiguiente, la ceguera es no solo un defecto, una deficiencia, sino tambien, una fuente de revelacion de aptitudes, una ventaja, una fuerza (VYGOTSKY, 1997, p. 99).

RIAEE - Revista Ibero-Americana de Estudos em Educação, Araraquara, v. 16, n. esp. 4, p. 3086-3105, dez. 2021. e-ISSN: 1982-5587 DOI: https://doi.org/10.21723/riaee.v16iesp.4.15600 
Durante a prática da atividade testar o teclado, os professores demonstraram algumas dificuldades, dentre elas: concentrar-se para realização da atividade, tendo em vista que era um grande grupo, e eles precisavam fazer uso da audição para ouvir o que o computador falava por meio do sintetizador de voz. O tato também foi um dos sentidos que os professores tiveram dificuldades por serem totalmente videntes. A digitação no teclado sem o uso da visão foi a maior dificuldade apresentada pelos professores.

Nesse sentido, Silva et al. (2018) demonstram que é necessário colocar-se no lugar do outro e observar que a superação que a pessoa cega necessita para entender-se na sociedade carece, muitas vezes, de olhares sem preconceito, da compreensão de como eles veem o mundo a partir do uso dos sentidos como o tato, a audição, o paladar e o olfato. Por meio da intervenção prática foi possível perceber que os professores em formação inicial foram compreendendo melhor sobre o processo inclusivo, no sentido de como as pessoas com deficiência visual aprendem e se inter-relacionam nos espaços da sociedade.

Após a realização da atividade testar o teclado, os professores, ainda vendados, foram convidados a explorar cada programa e sua usabilidade, tais como: edivox, jogos, jogavox, acesso à internet, dentre outros. Os vinte e cinco professores participantes do estudo não conseguiram finalizar as atividades propostas no programa Dosvox vendados. Nesse contexto, alguns estudos (PADILHA; OLIVEIRA, 2016; NUNES; LOMÔNACO, 2010; VYGOTSKY, 1997) evidenciam sobre a necessidade de o professor colocar-se no lugar do estudante e de conhecer as formas de aprendizado das pessoas com deficiência visual em vários espaços, sendo educacionais, sociais ou culturais.

Para finalizar o primeiro momento da intervenção prática, o professor Joaquim pediu para que os professores retirassem suas vendas e olhassem para a tela do computador/notebook para analisarem e refletirem sobre o que escreveram no programa Edivox, o qual se pode considerar como o Word utilizado por pessoas videntes. Todos os professores se surpreenderam, pois não conseguiram realizar com finalizações as atividades, das quais uma delas foi a realização da escrita do nome no programa. Sendo assim, um dos professores relata:

[...] foi importante esse momento, eu nunca havia colocado uma venda e ficado tanto tempo sem enxergar, realmente é muito difícil, a partir de hoje, vejo como de fato uma pessoa com deficiência visual vive, eu sei que fiquei pouco tempo sem enxergar, mas mudei minha concepção! Quero aprender mais sobre o uso da TADosvox para que eu possa utilizar em sala de aula com meus futuros alunos, caso tenha algum com deficiencia visual, assim como outros recursos possiveis e que visem o processo inclusivo deles (PROFESSOR EM FORMAÇÃO INICIAL, 2019). 
A intervenção prática realizada pelo professor Joaquim aos professores em formação inicial de Pedagogia partiu da concepção de Vygotsky (1991), no sentido de buscar a mediação entre eles e também a interação homem-ambiente pelo uso da linguagem. Para o teórico, "[...] a fala como tal, torna-se parte essencial do desenvolvimento cognitivo" (VYGOTSKY, 1991, p. 25). A partir do uso da linguagem, o professor Joaquim foi percebendo as carências expostas pelos professores sobre a TA. Então, ele foi mediando o uso da TA - Dosvox, envolvendo o processo inclusivo a partir de suas práticas e suas vivências durante a intervenção.

Em seguida, Joaquim levanta um questionamento aos professores: “[...] vocês se consideram preparados para receber uma pessoa com deficiência visual em sala de aula?". De modo geral, os professores responderam que não se encontram preparados, mas que fariam o possível para proporcionar meios que se pautem no processo inclusivo para o conhecimento de pessoas com essa deficiência.

Em linhas gerais, Prais e Rosa (2017, p. 131) ressaltam que “[...] a formação de professores é um dos pontos críticos que podem influenciar na qualitativa efetivação das políticas inclusivas e consolidação de inclusão escolar". Com a intenção de desmistificar este pensamento, esse estudo direcionou-se no sentido de contribuir com a formação inicial de professores, pensando no processo inclusivo em sala de aula. Sabe-se das dificuldades encontradas, mas incluir e ensinar é o papel fundamental de um professor.

No segundo momento, a intervenção foi mediada aos professores sem o uso das vendas. A intervenção obteve os mesmos direcionamentos da intervenção anterior, a qual também fez uso das atividades de programação da TA - Dosvox, edivox, jogos, jogavox, acesso à internet, dentre outros programas. Essa intervenção buscou explanar as ações do professor Joaquim frente ao processo de ensino e aprendizagem dos demais professores. Nesse sentido, o professor Joaquim usou a mediação por meio da linguagem e comandou as ações dos professores no uso do computador a partir dos sintetizadores de voz do programa Dosvox, ou seja, por meio da audição.

Ao que se refere ao uso da linguagem, Nunes; Lomonâco (2010, p. 56) salientam sua importância para o desenvolvimento humano, destacando que é inquestionável para o cego, pois " [...] a linguagem assume um papel ainda maior, porque as informações visuais a que ele não tem acesso podem ser parcialmente verbalizadas". Essa acessibilidade foi percebida durante toda a intervenção.

Durante a apresentação da TA - Dosvox em que os professores não fizeram uso das vendas, demonstraram-se bem impressionados com a habilidade e o conhecimento do 
professor Joaquim no uso da TA, compreenderam a importância de colocar-se no lugar do outro. Nesse sentido, vale evidenciar que durante o processo de intervenção uma professora relata ao professor Joaquim:

[...] professor, quando eu estava com os olhos vendados eu tive muitas dificuldades em manipular o teclado do computador e compreender os sons e comandos que a máquina e você transmitiam. Pois, fui desafiada a retirar o sentido que eu mais utilizo a minha visão. Agora que estou sem as vendas, ainda sinto algumas dificuldades, mas, a forma como você ensina é surpreendente, como pode, você não ver nada, e nos auxiliar, mostrando nossos erros, nós que estamos enxergando? Estou muito feliz em ter essa possibilidade de aprender com você, pois me mostrou um processo de ensino ao qual eu jamais iria compreender, mas a experiência que você me proporcionou e aos meus colegas me fez ver o mundo de outra forma, ou seja, como você vê, pelos sons, tato, olfato, de maneira mais inclusiva (PROFESSORA EM FORMAÇÃO INICIAL, 2019).

A Figura 4 apresenta o momento da intervenção sobre a TA - Dosvox para os professores sem o uso das vendas:

Figura 4 - Intervenção prática: apresentação da TA - Dosvox

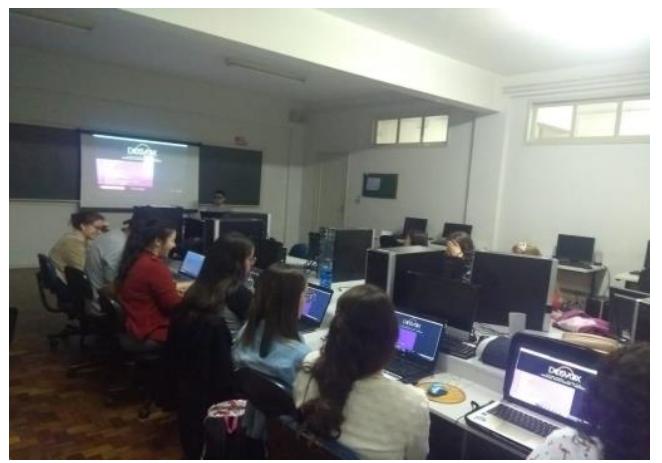

Fonte: Acervo das pesquisadoras (2019)

De modo geral, os professores apresentaram algumas dificuldades iniciais no processo de aprendizagem da TA - Dosvox, mas, ao final da intervenção, já estavam mais próximos da realidade vivenciada por pessoas com deficiência visual, no modo de como elas aprendem e fazem uso da TA.

É importante ressaltar que os professores necessitam desenvolver práticas que contextualizem a educação inclusiva, no sentido de possibilitar ao estudante uma equidade de condições para o conhecimento. Vygotsky (1997) salienta que o desenvolvimento das particularidades de uma pessoa cega deve ser respeitado.

No terceiro momento da intervenção, o professor Joaquim sugeriu que os professores colocassem em ação o que eles haviam aprendido no primeiro e segundo momento da intervenção sobre a TA - Dosvox. As ações tinham como propósito fazer com que os professores pudessem simular as práticas com estudantes com deficiência visual em sala de 
aula. Sendo assim, os professores deveriam, com base no que haviam aprendido, desenvolver metodologias e didáticas voltadas para o processo de ensino e aprendizagem destes estudantes.

Para consolidar essas práticas os professores utilizaram o computador/notebook como recursos didáticos durante o processo de ensino da TA - Dosvox.

Os professores formaram duplas para a intervenção, um deles representou o estudante cego, sendo vendado, e o outro professor fez o papel do (mediador) com o intuito de ensinar a TA a partir dos programas contidos no Dosvox, ou seja, o conhecimento básico e inicial para o processo de ensino.

Durante a intervenção, este estudo considerou algumas ações realizadas pelos professores, dentre elas: os professores que representaram os (mediadores) do conhecimento, demonstraram pouca paciência no momento da intervenção, pois, segundo eles, os professores que representavam os (estudantes cegos) não estavam realizando a atividade proposta. Em contrapartida, os (estudantes cegos) salientaram que não estavam conseguindo compreender as ações comandadas pelos professores (mediadores), pois estavam vendados e não estavam ouvindo os comandos atribuídos a eles, pois havia muitas pessoas falando ao mesmo tempo.

Observa-se diante deste contexto a ausência do uso de instrumentos e da linguagem entre professores (mediadores) e os professores que representaram os (estudantes cegos). Segundo Vygotsky (1991), a situação da inter-relação é essencial para o desenvolvimento de ações para a externalização da linguagem. Nesse sentido, e devido às práticas apresentadas pelos professores em formação inicial, é necessário que revejam e reflitam suas ações durante o processo de ensino e aprendizagem inclusivo, sendo indispensável que o professor compreenda de que forma os estudantes com deficiência visual aprendem. Para Vygostsky (1997), encontra-se nas pessoas cegas um desenvolvimento de memória maior do que nas pessoas videntes, porém, isso não dispensa a necessidade de qualificação do professor para o ensino com estes estudantes.

Destacam-se alguns estudos abordados por Vygostsky (1997) referentes ao desenvolvimento de pessoas com deficiência visual:

[...] o último estudo comparativo de E. Kretschmer (1928) mostrou que os cegos têm melhor memória verbal, mecânica e racional. A. Petzeld cita exatamente esse fato, estabelecido por uma série de investigações (A. Petzeld, 1925). Biirklen compilou opiniões de muitos autores que concordam em uma coisa: afirmam que nos cegos a memória se desenvolve com particular força, que geralmente ultrapassa a memória dos videntes (VYGOSTSKY, 1997, p. 105, tradução nossa) ${ }^{5}$.

5 [...] el ultimo estudio comparativo de E. Kretschmer (1928) demostró que los ciegos poseen una mejor memoria verbal, mecanica y racional. A. Petzeld cita ese mismo hecho, establecido por una serie de investigaciones (A. RIAEE - Revista Ibero-Americana de Estudos em Educação, Araraquara, v. 16, n. esp. 4, p. 3086-3105, dez. 2021. e-ISSN: 1982-5587 
Frente às práticas mediadas aos professores em formação inicial, foi possível observar que por estarem habituados apenas ao sentido visual, no momento em que foram vendados, se desestruturaram emocionalmente. Alguns professores que representaram os (mediadores) durante a intervenção começaram a falar muito alto com os outros professores que representavam os (estudantes cegos). Os professores mediadores acabaram pegando na mão dos estudantes cegos e realizaram as ações de forma mecânica, várias ações nesse sentido foram surgindo durante a intervenção. Porém, estas ações deveriam ser realizadas pelos estudantes cegos, de forma com que eles pudessem iniciar a apropriação do ensino da TA Dosvox. Esta intervenção mostra a importância de trabalhar mais com a educação inclusiva na formação inicial de professores.

Considerando as ações dos professores, tanto os que representaram os mediadores quanto os que representaram os estudantes cegos, observa-se a necessidade de refletir sobre os quatro pensamentos essenciais para o desenvolvimento e aprendizagem da criança retratados por Vygotsky (1991): a interação, a internalização, a mediação e a zona de desenvolvimento proximal. Estes pensamentos desvelam o processo de ensino e de aprendizagem, que quando não é mediado acaba determinando a falta de estrutura no pensamento e na linguagem dos estudantes. Portanto, “[...] o desenvolvimento da memória das crianças deve ser estudado não somente com respeito às mudanças que ocorrem dentro do próprio sistema de memória, mas, também, com respeito à relação entre memória e outras funções” (VYGOTSKY, 1991, p. 37).

Segundo o teórico, é necessário que o professor e os estudantes aprendam a interagir a partir das relações sociais e culturais em que estão inseridos. Essa interação se dá por meio da linguagem, e não foi possível de observar durante a intervenção prática realizada entre os professores. Nesse contexto, Alvaristo (2019, p. 28) ressaltou que o professor “[...] tem grande importância no desenvolvimento da criança, pois ele é responsável por mediar conhecimentos, estimulando-a a se superar e a se apropriar de novos conceitos para aprendizagem". Nesse sentido, o professor Joaquim ressalta aos professores frente à proposta de ensino pleiteada:

[...] observei que vocês tiveram muitas dificuldades em interagir um com o outro no momento do ensino da TA - Dosvox quero dizer-lhes que essa dificuldade na interação apresentada por vocês deve ser superada, pois é o primeiro passo para a execução do ensino de estudantes com deficiência visual. Pois estudantes, cegos como eu, necessitam da linguagem para aprender, isso exige paciência advinda do professor e do estudante. $O$ tato tem grande função para esse processo, não adianta

Petzeld, 1925). Biirklen compilo opiniones de muchos autores que coinciden en una cosa: afirman que en lo ciegos la memoria se desarrolla con particular fuerza, que supera por lo general la memoria de los videntes (VYGOSTSKY, 1997, p. 105). 
você pegar na mão do estudante e fazer por ele, é preciso que você o ensine como faz, e pode fazer isso usando alguns instrumentos e a linguagem necessária até com que o estude se aproprie da TA - Dosvox (PROFESSOR JOAQUIM, 2019).

Diante do respaldo suscitado pelo professor Joaquim, cabe um paralelo com a perspectiva de Vygotsky (1991, p. 23), o qual evidencia que a linguagem "[...] habilita as crianças a providenciarem instrumentos auxiliares na solução de tarefas difíceis, a superar a ação impulsiva, a planejar uma solução para um problema antes de sua execução e a controlar seu próprio comportamento". Portanto, é de suma importância que o professor no processo de sua formação inicial e após concluí-la procure novas especializações que possam contemplar suas práticas em sala de aula.

\section{Considerações finais}

O estudo teve como objetivo contribuir com a formação inicial de professores de um curso de Pedagogia por meio da Tecnologia Assistiva - Dosvox. Para tanto, este estudo contou com a participação de vinte e cinco professores de um curso de Pedagogia de uma Instituição Pública de Ensino Superior e um professor cego, o qual se nominou Joaquim. Diante da proposta, o estudo mediou intervenções práticas voltadas para o processo de ensino sobre o uso da TA - Dosvox, tendo em vista a concepção de ensino e aprendizagem inclusiva para estudantes com deficiência visual. As intervenções foram mediadas em três momentos pelo professor Joaquim aos professores em formação inicial; cada momento foi pensado com o intuito de contribuir com a formação destes professores de modo inclusivo à cultura digital, especificamente no uso da TA - Dosvox.

A TA - Dosvox vem sendo desenvolvida desde o ano de 1993 pelo Núcleo de Computação Eletrônica - NCE, da Universidade Federal do Rio de Janeiro - UFRJ. Possui uma tecnologia de fácil acesso em seu sistema, totalmente nacional, considerada o primeiro sistema comercial a sintetizar vocalmente textos genéricos para a língua portuguesa; esses textos são produzidos por meio de um sintetizador de voz, programado para realizar a leitura da tela do computador às pessoas cegas, e tem como intuito possibilitar a acessibilidade e a inclusão de pessoas com deficiência visual ao uso da tecnologia digital, desmistificando paradigmas de que o cego não consegue fazer uso do computador, assim, proporcionando às pessoas com deficiência visual maior acesso à comunicação e à interação por meio digital.

Nesse contexto e com base nas intervenções realizadas aos professores em formação inicial de um curso de Pedagogia foi possível verificar que os professores apresentaram dificuldades no processo de instalação do programa da TA - Dosvox; na privação dos olhos e,

RIAEE - Revista Ibero-Americana de Estudos em Educação, Araraquara, v. 16, n. esp. 4, p. 3086-3105, dez. 2021. e-ISSN: 1982-5587 
em alguns momentos, da audição durante a realização e manipulação tátil do computador para realização das atividades; no uso da linguagem; na inter-relação com os colegas, entre outros. Devido às práticas e ações apresentadas pelos professores em formação inicial se faz necessário rever e refletir sobre essas ações durante o processo educativo inclusivo.

Os resultados revelaram que as intervenções realizadas pelo professor Joaquim aos professores em formação inicial contribuíram com a aquisição de novas concepções sobre o processo de ensino e aprendizagem inclusivo da TA - Dosvox, assim como a se reconhecerem e se autoavaliarem pedagogicamente no processo de ensino inclusivo às pessoas com deficiência visual, principalmente no modo de ensinar e aprender com um professor cego, bem como a importância da alteridade durante a mediação em salas de aula.

\section{REFERÊNCIAS}

ALVARISTO, E. F. Uma ferramenta para elaboração de conceitos matemáticos para estudantes com deficiência visual: gráfico em pizza adaptado. 2019. 103 f. Dissertação (Mestrado em Ensino de Ciência e Tecnologia) - Universidade Tecnológica Federal do Paraná, Ponta Grossa, 2019.

ALVES, F. C. C. et al. Assistive technology applied to education of students with visual impairment. Pan American Journal of Public Health, Washington, p. 148-152, 2009.

BORGES, J. A. Do Braille ao Dosvox - Diferenças nas vidas dos cegos brasileiros. 2009. 343 f. Tese (Doutorado em Engenharias de sistemas e computação) - Universidade Federal do Rio de Janeiro, Rio de Janeiro. 2009.

BORGES. J. A. Projeto Dedinho - DOSVOX: Uma nova realidade educacional para Deficientes Visuais. Rio de Janeiro, 2002. Disponível em: http://intervox.nce.ufrj.br/dosvox/textos/artfoz.doc. Acesso em: 17 maio 2019.

BRASIL. Constituição da República Federativa do Brasil 1988. Brasília, DF, 1988. Disponível em: http://www.planalto.gov.br/ccivil_03/constituicao/constituicao.htm. Acesso em: 10 maio 2021.

BRASIL. Estatuto da Pessoa com Deficiência. Legislação Brasileira de Inclusão da pessoa com deficiência. Brasília, DF: Estatuto da Pessoa com Deficiência, 2015. Disponível em: http://www.planalto.gov.br/ccivil_03/_ato20152018/2015/lei/113146.htm. Acesso em: 19 fev. 2019.

BRASIL. Lei n. 9.394, de 20 de dezembro de 1996. Lei de Diretrizes e Bases da Educação Nacional. Estabelece as Diretrizes e Bases da Educação Nacional, 1996. Disponível em: http://www.planalto.gov.br/ccivil_03/leis/19394.htm. Acesso em: 15 jan. 2019.

BRASIL. Ministério da Educação. Declaração de Salamanca e Princípios, Políticas e Práticas na Área das Necessidades Educativas Especiais. Brasília, DF: MEC, 1994. 
BRASIL. Ministério da Educação. Secretaria de Educação Especial. Diretrizes nacionais para educação especial na educação básica. Brasília, DF: MEC; SEESP, 2001.

BRASIL. Ministério da Educação. Secretaria de Educação Especial. Política Nacional de Educação Especial na Perspectiva da Educação Inclusiva. Brasília, DF: MEC/SEESP, 2008. Disponível em: http://portal.mec.gov.br/arquivos/pdf/politicaeducespecial.pdf. Acesso em: 12 jan. 2019.

BRASIL. Saberes e Práticas da Inclusão. Estratégias para a educação de alunos com necessidades educacionais especiais. Brasília: MEC/SEF/SEESP. 2003. Disponível em: http://www.dominiopublico.gov.br/download/texto/me000428.pdf. Acesso em: 10 out. 2019.

DIAS, A.; FRANÇA, J.; BORGES, A. Jogavox: uma abordagem de aprendizagem colaborativa com pessoas deficientes visuais. Rio de Janeiro: NCE, UFRJ, 2014. 14 p.

DORZIAT, A. O profissional da inclusão escolar. Cadernos de Pesquisa, São Paulo, v. 43, n. 150, 2014. p. 986-1003, set./ dez.

GALVÃO FILHO. T. A. Tecnologia Assistiva para uma Escola Inclusiva: Apropriação, Demandas e Perspectivas. 2009. 346 f. Tese (Doutorado) - Universidade Federal da Bahia, 2009. Disponível em:

https://repositorio.ufba.br/ri/bitstream/ri/10563/1/Tese\%20Teofilo\%20Galvao.pdf. Acesso em: 10 ago. 2019.

GERHARDT, E. T; SILVEIRA, T. D. Métodos de pesquisa: planejamento e gestão para o desenvolvimento rural da SEAD/UFRGS. 2009. Porto Alegre, RS: Ed. da UFRGS.

KASSAR, M. C. M. Educação especial na perspectiva da educação inclusiva: desafios da implantação de uma política nacional, 2011. Educar em Revista, v. 41, n. 1, p. 61-79.

LÜDKE, M.; ANDRÉ, M. E. D. A. Pesquisa em educação: abordagens qualitativas. São Paulo: EPU, 1986.

MAZZILLO, B. I. Dosvox o que você deseja? Rio de Janeiro: Universidade Federal do Rio de Janeiro. 2010.

MORAN, J. M. A contribuição das tecnologias na educação. São Paulo. Papirus, 2013.

NUNES, S. LOMÔNACO, J. F. B. O aluno cego: preconceitos e potencialidades. Rev. Semestral da Associação Brasileira de Psicologia Escolar e Educacional, v. 14, n. 1, p. 55 64, 2010.

PADILHA, L. M. A.; OLIVEIRA, M. I. Conhecimento, trabalho docente e escola inclusiva. Journal of Research in Special Educational Needs, v. 16, n. 1, p. 318-322, 2016.

Disponível em: https://onlinelibrary.wiley.com/doi/epdf/10.1111/1471-3802.12294. Acesso em: 15 maio 2019. 
PRAIS, S. L. J.; ROSA, F. V. A formação de professores para a inclusão tratada na revista brasileira de educação especial: uma análise. Rev. Educação Especial, v. 30, n. 57, p. 129144, jan./abr. 2017.

SÁ, D. E.; CAMPOS, M. I.; SILVA, C. B. M. Atendimento educacional especializado: deficiência visual. Brasília: Ministério da Educação, Secretaria de Educação Especial, 2007.

SILVA, R. C. S. et al. Cegueira adquirida: implicações sociais, culturais e educacionais. Rev. Tecné, Episteme y Didaxis, 2018. Disponível em:

https://revistas.pedagogica.edu.co/index.php/TED/article/view/9066. Acesso em: 10 jun.2019.

SONZA, P. A.; SANTAROSA, C. M. L. Ambientes Digitais Virtuais: Acessibilidade aos Deficientes Visuais. Rev. Novas Tecnologias da Educação, 2003. Disponível em:http://seer.ufrgs.br/renote/article/viewFile/13637/7715. Acesso em: 09 ago. 2019.

VYGOTSKY, L. S. Fundamentos de defectología. In: Obras escolhidas. Moscú: Editorial Pedagógica, 1997.

VYGOTSKY, L. S. Pensamento e Linguagem. 3. ed. São Paulo: Martins Fontes, 1991.

\section{Como referenciar este artigo}

ALVARISTO, E. F.; SANTINELLO, J. As contribuições da Tecnologia Assistiva Dosvox para professores em formação inicial: intermediando práticas tecnológicas inclusivas. Revista Ibero-Americana de Estudos em Educação, Araraquara, v. 16, n. esp. 4, p. 3086-3105, dez. 2021. e-ISSN: 1982-5587. DOI: https://doi.org/10.21723/riaee.v16iesp.4.15600

Submetido em: $22 / 08 / 2021$

Revisões requeridas em: 30/10/2021

Aprovado em: 10/12/2021

Publicado em: 30/12/2021 